\title{
The islet endothelial cell: a novel contributor to beta cell secretory dysfunction in diabetes
}

\author{
Meghan F. Hogan ${ }^{1,2} \cdot$ Rebecca L. Hull ${ }^{1,2}$
}

Received: 3 January 2017 / Accepted: 2 March 2017 / Published online: 10 April 2017

(C) Springer-Verlag Berlin Heidelberg 2017

\begin{abstract}
The pancreatic islet is highly vascularised, with an extensive capillary network. In addition to providing nutrients and oxygen to islet endocrine cells and transporting hormones to the peripheral circulation, islet capillaries (comprised primarily of islet endothelial cells) are an important source of signals that enhance survival and function of the islet beta cell. In type 2 diabetes, and animal models thereof, evidence exists of morphological and functional abnormalities in these islet endothelial cells. In diabetes, islet capillaries are thickened, dilated and fragmented, and islet endothelial cells express markers of inflammation and activation. In vitro data suggest that this dysfunctional islet endothelial phenotype may contribute to impaired insulin release from the beta cell. This review examines potential candidate molecules that may mediate the positive effects of islet endothelial cells on beta cell survival and function under normal conditions. Further, it explores possible mechanisms underlying the development of islet endothelial dysfunction in diabetes and reviews therapeutic options for ameliorating this aspect of the islet lesion in type 2 diabetes. Finally, considerations regarding differences between human and rodent islet vasculature and the potentially unforeseen negative consequences of strategies to expand
\end{abstract}

Electronic supplementary material The online version of this article (doi:10.1007/s00125-017-4272-9) contains a slideset of the figures for download, which is available to authorised users.

Rebecca L. Hull

rhull@uw.edu

1 Division of Metabolism, Endocrinology and Nutrition, VA Puget Sound Health Care System (151), 1660 South Columbian Way, Seattle, WA 98108, USA

2 Department of Medicine, University of Washington, Seattle, WA, USA the islet vasculature, particularly under diabetic conditions, are discussed.

Keywords Beta cell · Capillary · Diabetes · Endothelial cell · Inflammation $\cdot$ Insulin secretion $\cdot$ Islet $\cdot$ Microvasculature . Review
Abbreviations
AGE Advanced glycation endproducts
COX2 Cyclooxygenase 2
CTGF Connective tissue growth factor
GK Goto-Kakizaki
HGF Hepatocyte growth factor
NOS3 Endothelial nitric oxide synthase
RAS Renin-angiotensin system
SDT Spontaneous Diabetic Torii
THBS1 Thrombospondin-1
VEGF Vascular endothelial growth factor
ZDF Zucker Diabetic Fatty

\section{Overview}

The pancreatic islet is a complex network of numerous cell types. The vast majority of islet research has focused on endocrine cells, chiefly beta and alpha cells, including mechanisms that control their development, function and turnover. However, the islet also includes several important nonendocrine cell types, including sympathetic and parasympathetic nerves and an extensive capillary network comprised of endothelial cells and pericytes [1-4]. The integrated function of all these cell types is required for normal islet function. This review will discuss the particular role of the islet endothelial cell in supporting beta cell function and health, together with 
emerging evidence that alterations in islet endothelial cell function and morphology may represent an important contributor to impaired insulin secretory function and survival of the beta cell in type 2 diabetes.

\section{Islet vasculature: not just a pretty tube}

While islets only constitute $1-2 \%$ of pancreas volume, they receive approximately $15 \%$ of the blood supply [5]. Islet vascular morphology is reviewed in detail elsewhere [1-4]. Briefly, islet vasculature comprises arterioles, which enter the islet and branch into tortuous capillary networks which, in rodents, have been suggested to contact virtually every islet endocrine cell [6]. These capillaries in turn then converge with collecting venules outside the islet [1].

Significant differences exist in islet vascularisation and morphology in human islets compared with those from rodents; specifically, islet capillaries are larger and significantly less dense in human islets (Fig. $1[7,8]$ ). This observation is in line with other differences that have been noted between these species with respect to islet morphology and function, most notably the recent observation that human islets contain fewer, relatively large nerve fibres, compared with the extensive network of fine nerve fibres found in rodent islets [9]. This finding is expected, given that nerve fibres run parallel to islet capillaries. The impact of the differences in islet vasculature between human and rodent islets that pertain to islet endocrine function/viability has yet to be determined; although a few studies have successfully isolated and cultured human islet endothelial cells $[10,11]$, providing hope for new insight into this interesting area. Thus, additional work will be required to assess the translatability of the findings discussed in the subsequent sections, which emanate almost entirely from work in animal models.

Islet capillaries are lined by a highly fenestrated endothelium, with the density of fenestrae in islet endothelial cells being ten times greater than that in the exocrine pancreas.
These fenestrae are critical for the rapid and reciprocal exchange of nutrients and hormones between the bloodstream and islet cells. Maintenance of endothelial fenestration and cell viability requires vascular endothelial growth factor (VEGF), which can be produced by numerous cell types, including vascular-associated pericytes and macrophages. In the islet, the beta cell is a major source of VEGF production. Indeed, beta cell-specific deletion of VEGF-A in mice results in islet capillary loss and decreased insulin release in vivo [12]. Of note, insulin is also a major signal for endothelial cell function, for example, it is required for phosphorylation (activation) of endothelial nitric oxide synthase (NOS3), which catalyses production of the vasodilator nitric oxide (NO). Thus, signals produced by the beta cell impinge on the islet endothelial cell, contributing to overall islet health.

In turn, islet endothelial cells produce many molecules that impinge on the beta cell (Fig. 2; data reviewed in detail below). The concept of a signalling loop operating between the islet microvasculature and beta cell is well established in rodents and has been reviewed elsewhere [2-4]. Many studies have focused on the importance of the islet endothelial cell during beta cell development or in driving the programing of pluripotent stem cells toward a beta cell lineage, and revascularisation of islets following transplantation. This combined body of literature has been instrumental in developing our understanding of how endothelial-beta cell crosstalk occurs in the adult pancreas.

\section{The role of islet endothelial cells in supporting adult beta cell growth and function}

Islet endothelial cells produce growth factors and other molecules that enhance beta cell proliferation, survival and function under physiological conditions. In mice, beta cell expansion during pregnancy is preceded by growth of the islet vasculature, associated with increased islet endothelial cell proliferation and islet endothelial expression of hepatocyte
Fig. 1 Schematic showing substantial differences in islet angioarchitecture between (a) rodents and (b) humans. (a) Rodent islets contain an extensive network of fine, tortuous capillaries, as reviewed in detail in [1-3]. (b) In contrast, human islets contain fivefold fewer, larger vessels that are significantly less tortuous. Based, in part, on data from $[7,8]$
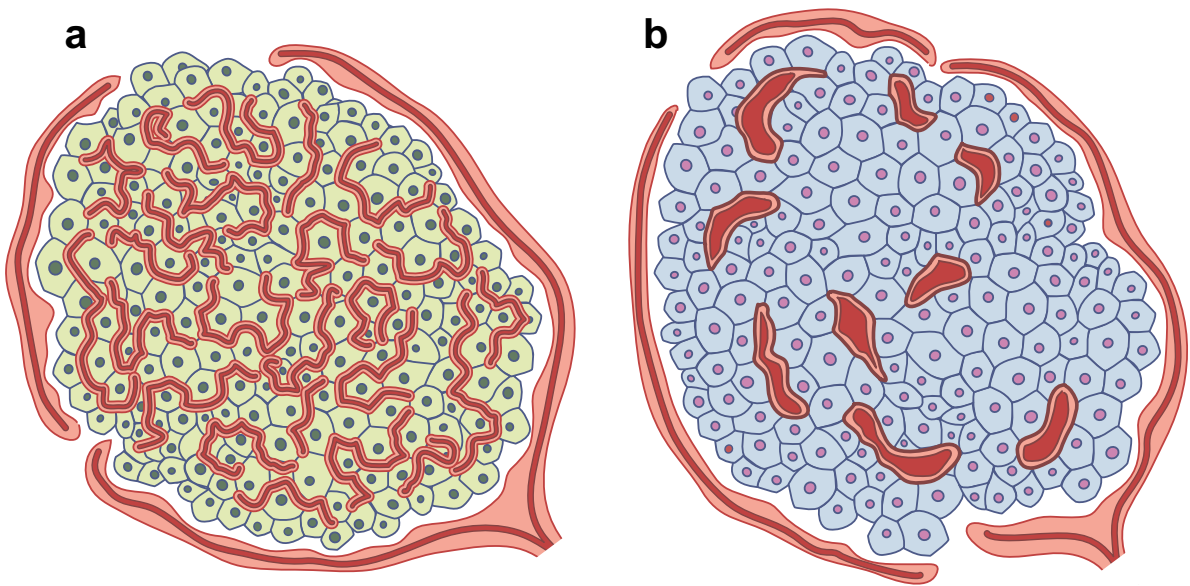


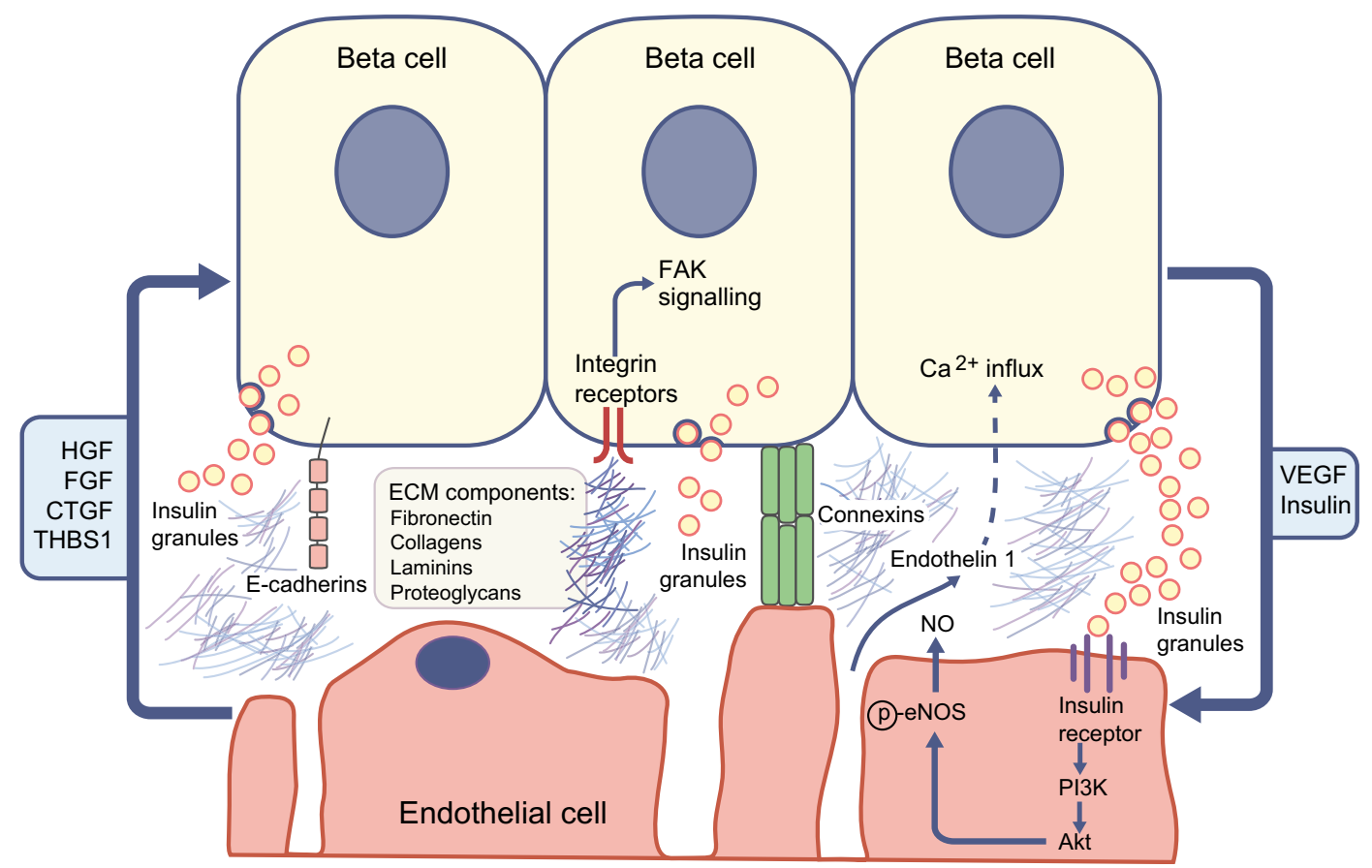

Fig. 2 Diagram summarising the main factors regulating the islet beta cell-endothelial cell axis. Based, in part, upon $[2,4]$. Islet endothelial cells produce factors that enhance beta cell proliferation, survival and function under physiological conditions, including HGF, fibroblast growth factor (FGF), CTGF and THBS1. Additional islet endothelial cell-secreted factors modulate beta cell function; for example, endothelin-1 increases insulin release from isolated mouse islets, possibly by triggering calcium influx into beta cells. Extracellular matrix (ECM) molecules (e.g. fibronectin, collagens, laminins) also affect insulin expression and release from beta cells, partly via integrins (heterodimeric cell-surface receptors with broad specificity for ECM molecules) and activation of downstream signalling pathways, including focal adhesion kinase (FAK). E-cadherin and connexins govern cell-matrix interaction and cell-cell interactions, respectively, and thus may also mediate islet endothelial-beta crosstalk. Vice versa, beta cell-secreted factors can also impact islet endothelial cell function. For example, beta cell-derived insulin binds to the insulin receptor on endothelial cells, resulting in downstream activation of phosphoinositide 3-kinase (PI3K) and Akt and subsequent phosphorylation (p) and activation of NOS3, leading to the production of vasodilatory NO. Furthermore, VEGF, required for maintenance of endothelial fenestration and cell viability, is produced by islet beta cells and is a major source of VEGF in the islet growth factor (HGF) [13]. Johansson et al demonstrated that incubation of primary beta cells with secreted factors from islet endothelial cells increased beta cell proliferation in vitro. This effect was dependent on HGF production by islet endothelial cells, which in turn required VEGF production from beta cells [13]. Other islet endothelial-derived factors can also modulate beta cell expansion. Haploinsufficiency of $C \operatorname{tg} f$ (the gene encoding connective tissue growth factor [CTGF]) resulted in decreased beta cell proliferation during pregnancy [14], while genetic deletion of the anti-angiogenic factor thrombospondin-1 (THBS1), results in islet hyperplasia in young adult mice [15]. Despite the opposing effects of CTGF vs THBS1 deficiency on beta cell regeneration, both molecules exert positive effects on beta cell function. For example, deletion of $C \operatorname{tg} f$ from the islet endocrine cell lineage (under a paired box protein $[\mathrm{PAX}] 6$ promoter) resulted in reduced insulin release and the development of gestational diabetes, suggesting that this defect may have arisen from modulation of islet morphogenesis during development since CTGF is only expressed in the vasculature of the adult islet. Thbs 1 knockout mice also exhibited impaired glucose tolerance and reduced insulin release in vivo; this occurred in the absence of changes in insulin sensitivity or body weight. Moreover, islets from Thbs 1 knockout mice exhibited a reduction in glucosestimulated insulin release, along with reduced glucose oxidation and increased lactate production, whereas insulin release in response to $\mathrm{KCl}$ and insulin content were unaffected. [15]. The effects of Thbs 1 deletion on beta cell function appear more durable that its effects on islet hyperplasia. Specifically, no difference in islet mass was observed in Thbsl knockout mice beyond 16 weeks of age (up to 1 year of age), while glucose intolerance and reduced insulin release persisted in older animals [16].

In vitro studies have revealed additional factors secreted from islet endothelial cells that modulate beta cell function. Endothelin-1 increases insulin release from isolated mouse islets, an effect that may include direct triggering of calcium influx into beta cells [17] or may occur via an indirect effect on the alpha cell [18]. Johansson et al performed a comprehensive study examining the effects of multiple endothelialderived molecules on insulin release in vitro. These studies were based on a model where exposure of whole islets to 
factors secreted from cultured islet endothelial cells resulted in no change in basal insulin release, but significantly enhanced glucose-stimulated insulin release and increased insulin content [19], similar to findings from a subsequent study [20]. This increased insulin release was not prevented by inhibiting endothelin-1 receptor activation, inhibiting cyclooxygenase 2 (COX2), or using blocking antibodies against HGF or THBS1, but was inhibited with a blocking antibody against the $\beta 1$ subunit of laminin [19].

Laminins are a family of extracellular matrix molecules and are a major component of the islet capillary basement membrane [21, 22]. Exposure of beta cells to various laminin isoforms has been shown to increase insulin gene transcription and insulin release $[19,22,23]$. This effect is at least partly dependent on integrins, a family of heterodimeric cell-surface receptors with broad specificity for extracellular matrix molecules (e.g. laminins, collagens, fibronectin), some of which are expressed by the beta cell $[21,23]$, and activation of downstream signalling pathways including focal adhesion kinase [24]. Accordingly, other extracellular matrix molecules that can also signal through integrins have been shown to increase insulin expression or release [25]. These findings suggest that islet endothelial-derived extracellular matrix molecules are important for beta cell function, and their integrin receptors may represent a therapeutic target for modulation of insulin release and beta cell survival. Other receptors governing cellmatrix interactions (e.g. E-cadherin) or cell-cell interactions (e.g. connexins) may also be important in mediating islet endothelial-beta cell crosstalk (these are reviewed in [4]).

\section{Abnormal islet endothelial structure and function in diabetes}

In human pancreases from individuals with type 2 diabetes, islet capillary morphology is abnormal. An increase in capillary density is observed, which is accompanied by thickening and fragmentation of islet capillaries (Fig. 3 and [7, 26]). Altered islet capillary morphology has also been described in a variety of rodent models of diabetes [20, 27-32]. Islet capillary loss, which is not a feature of human islets in type 2 diabetes, has been observed in Zucker Diabetic Fatty (ZDF) rats from 12 weeks of age [29], in 1-year-old diabetic Otsuka Long-Evans Tokushima fatty (OLETF) rats [30] and in $d b / d b$ mice on the naturally-occurring $\mathrm{C} 57 \mathrm{BL} / \mathrm{Ks}$ background at 4 months of age [28, 31], but not in $d b / d b$ mice backcrossed on to a C57BL/6J background at 4 months of age [20]. All of these animal models, along with Goto-Kakizaki (GK) diabetic and Spontaneous Diabetic Torii (SDT) rats, also exhibit features that are more in line with the observations in humans. Specifically, these include capillary hypertrophy, which occurs early in the course of disease in ZDF rats [29] and precedes diabetes in SDT rats [32], in addition to irregular capillary morphology, thickening and/or dilation [20, 27-32]. Islet fibrosis is also widely reported [27, 28, 30-33] and has also been documented in human type 2 diabetes [34]. In addition, islet oedema/haemorrhage has been reported in ZDF and SDT rats and in $d b / d b$ mice $[28,29,32]$, while hypertrophy and evidence of myofibroblast transition of pericytes has also been documented in $d b / d b$ mice [28, 34]. These last two features have not been reported in humans. Of note, the observation that morphological abnormalities seen in islet capillaries in human type 2 diabetes are recapitulated by a number of animal models of diabetes is encouraging and suggests that data from these models may be relevant to human disease.

Increased islet perfusion has been described in animal models of impaired glucose tolerance and diabetes [35, 36] and glucose-mediated vasodilation is exacerbated in isolated islet arterioles from alloxan-diabetic mice [37]. Of note, increases in islet blood flow do not necessarily correlate with increases in insulin release, even under physiological conditions [38].

Endothelial dysfunction has been shown to underlie diabetic microvascular complications [39, 40]. Biochemical evidence of endothelial dysfunction in islets has been documented in rodent models of diabetes [20, 27]. Specifically, upregulation of genes involved in vascular tone, angiogenesis, fibrinolysis, oxidative stress and inflammation were observed in islets from GK diabetic rats [27] at 10 weeks of age. Similarly, primary islet endothelial cells isolated from 8 -week-old $d b / d b$ mice exhibit increases in markers of inflammation, cell adhesion and vasoconstriction, together with markers of decreased vasodilation and accumulation of advanced glycation endproducts (AGE) [20].

Several studies have proposed cellular mediators of decreased islet endothelial cell function and viability under diabetic conditions. In line with clinical data showing that hyperglycaemia is a major factor underlying the development of diabetic microvascular complications [41], short-term normalisation of glucose levels with phlorizin in $\mathrm{db} / \mathrm{db}$ mice ameliorated the decrease in NOS3 protein levels seen in islets from individuals with diabetes [20]. Additionally, high glucose induced apoptosis in primary cultured human islet endothelial cells [10]. Levels of AGEs are increased with hyperglycaemia and associated with endothelial dysfunction in humans with diabetes [42] and with markers of islet endothelial dysfunction in $d b / d b$ mice [20]. Administration of AGEs to immortalised islet endothelial cells in vitro resulted in upregulation of prostaglandin $\mathrm{E}_{2}$ synthesis and activation of COX2 and NFKB signalling, leading to decreased cell viability and apoptosis [43].

Additional support for the concept that 'diabetic' islet endothelial cells are dysfunctional comes from the type 1 diabetes literature. Specifically, stimulation of islet endothelial cell regeneration by administration of endothelial progenitor cells 
Fig. 3 Schematic showing differences in islet capillary morphology and density between (a) humans without diabetes and (b) those with type 2 diabetes. (b) Islet capillaries in individuals with diabetes exhibit altered morphology and are irregular in their appearance. Intra- (but not peri-) islet capillaries exhibit thickening, fragmentation and, in some instances, loss of cellularity. Islet capillary density is increased by $36 \%$ in individuals with diabetes vs those without diabetes. Based, in part, on data from $[7,26]$
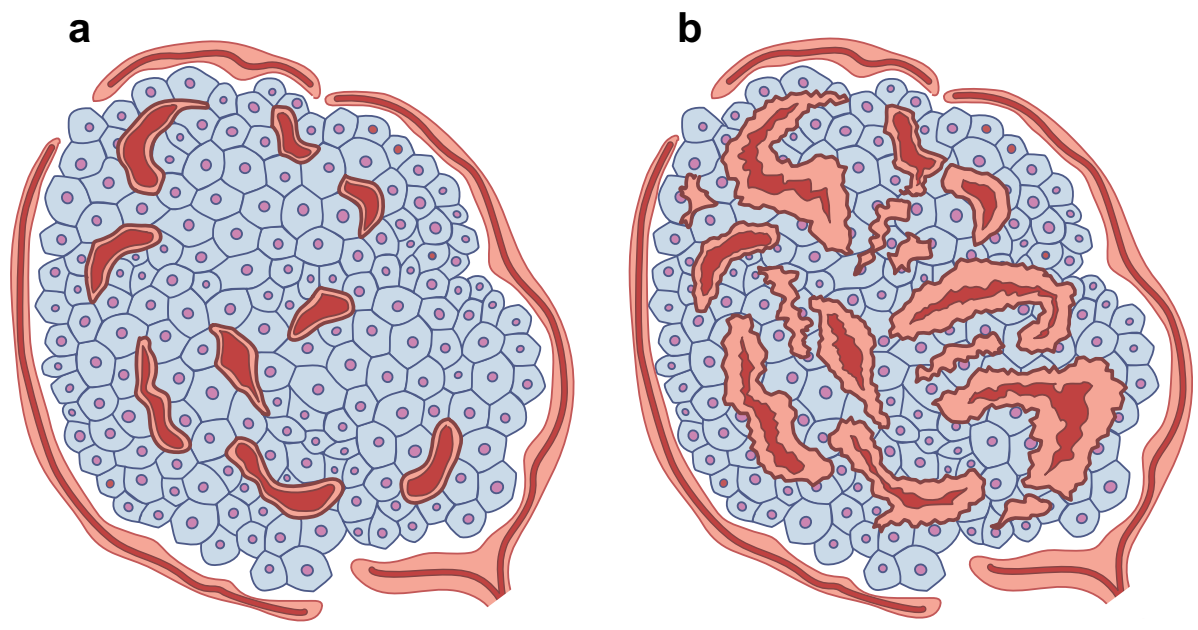

from diabetic NOD mouse donors did not result in beta cell regeneration in NOD mouse pancreases, thereby limiting the ability of these animals to respond to blood glucose-lowering immunomodulatory (immunoglobulin [Ig]-GAD2) therapy [44]. In contrast, the formation of new islet endothelial cells from endothelial progenitor cells from animals without diabetes was able to rescue this effect.

Only one study to date has investigated the possible impact of islet endothelial dysfunction in diabetes on insulin release from isolated islets [20]. Here, we showed that culture of immortalised islet endothelial cells with a cocktail of components designed to mimic the diabetic milieu of the islet (glucose, fatty acids, insulin and proinflammatory cytokines) resulted in a gene expression profile similar to that seen in islet endothelial cells from mouse models of diabetes. This is in line with previous work showing that exposing primary rat islet endothelial cells to diabetes-associated cytokines upregulates inducible nitric oxide synthase [45]. Exposure of isolated islets to secreted factors from these cells resulted in a significant decrease in insulin release relative to islets exposed to secreted factors from 'normal' islet endothelial cells [20]. Based on these data, it is likely that islet endothelial dysfunction contributes to impaired beta cell function in diabetes. Mediators of this effect may include decreases in one or more of the factors already known to mediate the beneficial effects of islet endothelial cells on beta cell function and survival, including those discussed above (i.e. decreases in HGF, THBS1, CTGF or laminins [13-16, 19]), and/or upregulation of additional, as yet unidentified factors that could impair insulin release.

\section{Potential therapies}

As mentioned above, normalisation of hyperglycaemia in rodent models of diabetes has beneficial effects on some markers of islet endothelial dysfunction [20], and anti- hyperglycaemic therapies have been shown to normalise islet capillary morphology [29] and islet blood flow [46]. Use of the IL-1 receptor antagonist in diabetic GK rats resulted in decreased expression of some, but not all, genes related to islet oxidative stress and endothelial activation [27].

Morphological abnormalities in the islet vasculature of rodent models of diabetes are also improved with blockade of the renin-angiotensin system (RAS), specifically pharmacological treatment with angiotensin converting enzyme inhibitors (perindopril) or angiotensin II type 1 receptor blockers (candesartan, irbesartan, losartan) [31,33]. Angiotensin 1-7, which antagonises the action of the classical arm of the RAS, has been shown to normalise islet vascular density and increase islet NOS3 protein levels, in addition to having beneficial effects on beta cell mass and function in a rat model of type 2 diabetes [47]. Further, in vitro treatment of immortalised islet endothelial cells with angiotensin 1-7 antagonised the pro-apoptotic effects of palmitate treatment, specifically via decreasing reactive oxygen species (ROS) and c-Jun N-terminal kinase (JNK) activation, resulting in increased phosphorylation of NOS3 and Akt [48].

Other clinically used therapies, such as glucagon-like peptide-1 (GLP-1), statins or COX2 inhibitors, have also been shown to exert protective effects on cultured primary or immortalised islet microvascular endothelial cells by antagonising stress signalling pathways in cells exposed to high glucose [10], oxidised protein products [49] or AGEs [43]. Whether these therapies are effective in normalising abnormalities in the islet vasculature in individuals with diabetes in vivo is yet to be determined.

\section{Considerations for future research and therapies: too much of a good thing}

While islet vasculature is clearly important for the normal survival and function of the beta cell, three recent studies call 
for caution in assuming that strategies to increase islet vasculature are universally positive. First, Agudo et al demonstrated that mice with constitutive Vegf overexpression under the rat insulin promoter developed islet hypervascularisation. This was associated with a progressive loss of beta cells, decreased insulin release and glucose intolerance, accompanied by islet macrophage infiltration and increased islet expression of chemokines and proinflammatory cytokines [50]. Feng et al utilised mice with transgenic expression of the receptor tyrosine kinase c-Kit under the rat insulin promoter, as a means to increase beta cell production of VEGF [51]. Under normal, chow-fed conditions, beta cell overexpression of cKit was associated with increased islet VEGF levels and increases in islet capillary density, beta cell mass and glucose tolerance. In contrast, when fed a high-fat diet, these same mice exhibited capillary expansion in association with impaired glucose tolerance, increased beta cell apoptosis and reduced beta cell mass. Additionally, increases in islet macrophage infiltration and proinflammatory cytokine production were also observed in these animals. The negative consequences of islet endothelial cell expansion are not limited to interventions that target VEGF specifically, since aged Thbs 1 knockout mice also exhibit islet hypervascularisation in association with impaired insulin release and glucose tolerance [16].

Importantly, detrimental effects of Vegf overexpression and/or islet hypervascularisation do not require life-long or even chronic increases in beta cell VEGF production. Brissova et al showed that doxycycline-induced overexpression of VEGF in beta cells for just 1 week in adult mice resulted in significant capillary overgrowth, leading to beta cell loss and the development of diabetes [52]. Interestingly, this phenotype was entirely reversible. Withdrawal of doxycycline treatment after the development of diabetes resulted in complete normalisation of islet vasculature, beta cell area and glucose homeostasis, so that 6 weeks after doxycycline withdrawal, islets were indistinguishable from those in mice without doxycycline treatment. This highlights the exquisite regulation of islet endothelial-beta cell crosstalk and suggests that there is a set point for the ratio of islet endothelial cells:beta cells that is tightly defended. In line with the two studies discussed above, Brissova and colleagues also observed a VEGF-dependent increase in the number of islet macrophages. In their study, however, in the context of low VEGF levels (i.e. following withdrawal of doxycycline) these macrophages were required for beta cell regeneration, suggesting that whether these macrophages mediate destructive or beneficial effects on the beta cell depends on the prevailing level of VEGF production and its downstream effects on the islet endothelial cell.

Taken together, these studies indicate that increasing islet VEGF levels and/or inducing islet hypervascularisation, especially under conditions of obesity and insulin resistance, results in inflammation and can negatively affect beta cell function. Thus, alternative strategies will be required to improve islet vascular/endothelial viability and function in order to determine whether this approach could be beneficial in the treatment of type 2 diabetes in humans.

In summary, a growing body of evidence supports the concept that the islet vasculature, and islet endothelial cells in particular, are sources of multiple critical signals that impinge on the beta cell (see summary text box). These enhance beta cell survival and function under normal conditions but in diabetes they contribute to impaired beta cell function and viability. The islet endothelial cell, therefore, provides a novel target for glucose-lowering therapies.

\section{Summary}

Not just a pretty tube

In addition to providing a conduit for nutrients and hormones to and from the peripheral circulation, the islet vasculature is a source of critical signals that support normal beta cell survival and function

Beta cells also produce factors (e.g. insulin and VEGF) that are beneficial for islet endothelial cells

Islet vasculature in diabetes

Islet capillaries are thickened and fragmented in human type 2 diabetes and animal models thereof. Islet endothelial cells also exhibit an inflammatory, pro-adhesive phenotype

We recently showed that 'diabetic' islet endothelial cells are no longer capable of supporting insulin release, suggesting that islet endothelial dysfunction in diabetes contributes to impaired beta cell function

\section{Potential treatments}

Strategies to normalise hyperglycaemia can mitigate the dysfunctional phenotype of islet endothelial cells in diabetes, along with therapies targeting the renin-angiotensin system, $\mathrm{IL}-1 \beta$ signalling and other pathways

\section{Too much of a good thing}

Approaches that increase islet vascularisation, especially under conditions of obesity and insulin resistance, are detrimental for the islet, resulting in inflammation, impaired insulin release and beta cell death. Thus, caution should be used in extrapolating the beneficial effects of the islet vasculature under normal conditions to the situation of metabolic disease 
Acknowledgements As a result of the limit on the number of references allowed, many excellent papers in this field could not be included. However, these additional publications were important in shaping this review; we apologise to those whose work was not cited directly. We thank S. Zraika and A. Aplin, both in the Research Service at VA Puget Sound Health Care System, Seattle, WA, USA, for valuable discussions related to the writing of this article.

Funding The authors' work in this area is supported by the Department of Veterans Affairs, VA Puget Sound Health Care System (Seattle, WA, USA), Seattle Institute for Biomedical and Clinical Research (Seattle, WA, USA) and National Institutes of Health grants R01 DK088082 (RLH), F32 DK109584 (MFH) and P30 DK017047 (University of Washington Diabetes Research Center).

Duality of interest The authors declare that there is no duality of interest associated with this manuscript.

Contribution statement RLH conceived the outline for this review. All authors reviewed and discussed the relevant literature, and were responsible for drafting the article and revising it critically for important intellectual content. All authors approved the version to be published.

\section{References}

1. Bonner-Weir S (1993) The microvasculature of the pancreas, with emphasis on that of the islets of Langerhans. In: Go VLW, DiMagno ER, Gardner JD, Lebenthal FP, Reber HA, Scheele GA (eds) The pancreas: biology, pathobiology, and disease. Raven Press, New York, pp 759-768

2. Olsson R, Carlsson PO (2006) The pancreatic islet endothelial cell: emerging roles in islet function and disease. Int J Biochem Cell Biol 38:492-497

3. Richards OC, Raines SM, Attie AD (2010) The role of blood vessels, endothelial cells, and vascular pericytes in insulin secretion and peripheral insulin action. Endocr Rev 31:343-363

4. Peiris H, Bonder CS, Coates PT, Keating DJ, Jessup CF (2014) The beta-cell/EC axis: how do islet cells talk to each other? Diabetes 63: $3-11$

5. Jansson L, Hellerstrom C (1983) Stimulation by glucose of the blood flow to the pancreatic islets of the rat. Diabetologia 25:45-50

6. Kragl M, Lammert E (2010) Basement membrane in pancreatic islet function. Adv Exp Med Biol 654:217-234

7. Brissova M, Shostak A, Fligner CL et al (2015) Human islets have fewer blood vessels than mouse islets and the density of islet vascular structures is increased in type 2 diabetes. J Histochem Cytochem 63:637-645

8. Carlsson PO, Palm F, Mattsson G (2002) Low revascularization of experimentally transplanted human pancreatic islets. J Clin Endocrinol Metab 87:5418-5423

9. Rodriguez-Diaz R, Abdulreda MH, Formoso AL et al (2011) Innervation patterns of autonomic axons in the human endocrine pancreas. Cell Metab 14:45-54

10. Favaro E, Miceli I, Bussolati B et al (2008) Hyperglycemia induces apoptosis of human pancreatic islet endothelial cells: effects of pravastatin on the Akt survival pathway. Am J Pathol 173:442-450

11. Sordi V, Ferri A, Ceserani V et al (2017) Establishment, characterization and long-term culture of human endocrine pancreas-derived microvascular endothelial cells. Cytotherapy 19:141-152

12. Brissova M, Shostak A, Shiota M et al (2006) Pancreatic islet production of vascular endothelial growth factor-a is essential for islet vascularization, revascularization, and function. Diabetes 55:2974 2985

13. Johansson M, Mattsson G, Andersson A, Jansson L, Carlsson PO (2006) Islet endothelial cells and pancreatic beta-cell proliferation: studies in vitro and during pregnancy in adult rats. Endocrinology 147:2315-2324

14. Pasek RC, Dunn JC, Elsakr JM, Aramandla M, Matta AR, Gannon $\mathrm{M}$ (2016) Connective tissue growth factor is critical for proper betacell function and pregnancy-induced beta-cell hyperplasia in adult mice. Am J Physiol Endocrinol Metab 311:E564-E574

15. Olerud J, Mokhtari D, Johansson M et al (2011) Thrombospondin1: an islet endothelial cell signal of importance for beta-cell function. Diabetes 60:1946-1954

16. Drott CJ, Olerud J, Emanuelsson H, Christoffersson G, Carlsson PO (2012) Sustained beta-cell dysfunction but normalized islet mass in aged thrombospondin-1 deficient mice. PLoS One 7: e47451

17. Gregersen S, Thomsen JL, Brock B, Hermansen K (1996) Endothelin-1 stimulates insulin secretion by direct action on the islets of Langerhans in mice. Diabetologia 39:1030-1035

18. Brock B, Gregersen S, Kristensen K et al (1999) The insulinotropic effect of endothelin-1 is mediated by glucagon release from the islet alpha cells. Diabetologia 42:1302-1307

19. Johansson A, Lau J, Sandberg M, Borg LA, Magnusson PU, Carlsson PO (2009) Endothelial cell signalling supports pancreatic beta cell function in the rat. Diabetologia 52:2385-2394

20. Hogan MF, Liu AW, Peters MJ et al (2017) Markers of islet endothelial dysfunction occur in male $\mathrm{db} / \mathrm{db}$ mice and may contribute to reduced insulin release. Endocrinology 158:293-303

21. Jiang FX, Naselli G, Harrison LC (2002) Distinct distribution of laminin and its integrin receptors in the pancreas. J Histochem Cytochem 50:1625-1632

22. Nikolova G, Jabs N, Konstantinova I et al (2006) The vascular basement membrane: a niche for insulin gene expression and beta cell proliferation. Dev Cell 10:397-405

23. Parnaud G, Hammar E, Rouiller DG, Armanet M, Halban PA, Bosco D (2006) Blockade of beta1 integrin-laminin-5 interaction affects spreading and insulin secretion of rat beta-cells attached on extracellular matrix. Diabetes 55:1413-1420

24. Rondas D, Tomas A, Soto-Ribeiro M, Wehrle-Haller B, Halban PA (2012) Novel mechanistic link between focal adhesion remodeling and glucose-stimulated insulin secretion. J Biol Chem 287:24232436

25. Kaido T, Yebra M, Cirulli V, Rhodes C, Diaferia G, Montgomery AM (2006) Impact of defined matrix interactions on insulin production by cultured human beta-cells: effect on insulin content, secretion, and gene transcription. Diabetes 55:2723-2729

26. Shah P, Lueschen N, Ardestani A et al (2016) Angiopoetin-2 signals do not mediate the hypervascularization of islets in type 2 diabetes. PLoS One 11:e0161834

27. Lacraz G, Giroix MH, Kassis N et al (2009) Islet endothelial activation and oxidative stress gene expression is reduced by IL-1Ra treatment in the type 2 diabetic GK rat. PLoS One 4:e6963

28. Nakamura M, Kitamura H, Konishi S et al (1995) The endocrine pancreas of spontaneously diabetic $\mathrm{db} / \mathrm{db}$ mice: microangiopathy as revealed by transmission electron microscopy. Diabetes Res Clin Pract 30:89-100

29. Li X, Zhang L, Meshinchi S et al (2006) Islet microvasculature in islet hyperplasia and failure in a model of type 2 diabetes. Diabetes 55:2965-2973

30. Mizuno A, Noma Y, Kuwajima M, Murakami T, Zhu M, Shima K (1999) Changes in islet capillary angioarchitecture coincide with impaired B cell function but not with insulin resistance in male Otsuka-Long-Evans-Tokushima fatty rats: dimorphism of the diabetic phenotype at an advanced age. Metabolism 48:477-483 
31. Shao J, Iwashita N, Ikeda F et al (2006) Beneficial effects of candesartan, an angiotensin II type 1 receptor blocker, on betacell function and morphology in $\mathrm{db} / \mathrm{db}$ mice. Biochem Biophys Res Commun 344:1224-1233

32. Masuyama T, Komeda K, Hara A et al (2004) Chronological characterization of diabetes development in male Spontaneously Diabetic Torii rats. Biochem Biophys Res Commun 314:870-877

33. Tikellis C, Wookey PJ, Candido R, Andrikopoulos S, Thomas MC, Cooper ME (2004) Improved islet morphology after blockade of the renin-angiotensin system in the ZDF rat. Diabetes 53:989-997

34. Hayden MR, Patel K, Habibi J et al (2008) Attenuation of endocrine-exocrine pancreatic communication in type 2 diabetes: pancreatic extracellular matrix ultrastructural abnormalities. J Cardiometab Syndr 3:234-243

35. Jansson L (1994) The regulation of pancreatic islet blood flow. Diabetes Metab Rev 10:407-416

36. Carlsson PO, Berne C, Jansson L (1998) Angiotensin II and the endocrine pancreas: effects on islet blood flow and insulin secretion in rats. Diabetologia 41:127-133

37. Lai EY, Jansson L, Patzak A, Persson AE (2007) Vascular reactivity in arterioles from normal and alloxan-diabetic mice: studies on single perfused islets. Diabetes 56:107-112

38. Jansson L (1985) Dissociation between pancreatic islet blood flow and insulin release in the rat. Acta Physiol Scand 124:223-228

39. Cosentino F, Luscher TF (1998) Endothelial dysfunction in diabetes mellitus. J Cardiovasc Pharmacol 32 Suppl 3:S54-S61

40. De Mattia G, Bravi MC, Laurenti O et al (2008) Endothelial dysfunction and oxidative stress in type 1 and type 2 diabetic patients without clinical macrovascular complications. Diabetes Res Clin Pract 79:337-342

41. The Diabetes Control and Complications Trial Research Group (1993) The effect of intensive treatment of diabetes on the development and progression of long-term complications in insulin-dependent diabetes mellitus. N Engl J Med 329:977-986

42. Tan KC, Chow WS, Ai VH, Metz C, Bucala R, Lam KS (2002) Advanced glycation end products and endothelial dysfunction in type 2 diabetes. Diabetes Care 25:1055-1059
43. Lan KC, Chiu CY, Kao CW et al (2015) Advanced glycation end-products induce apoptosis in pancreatic islet endothelial cells via NF-kappaB-activated cyclooxygenase-2/prostaglandin E2 up-regulation. PLoS One 10:e0124418

44. Wan X, Guloglu FB, Vanmorlan AM et al (2013) Recovery from overt type 1 diabetes ensues when immune tolerance and beta-cell formation are coupled with regeneration of endothelial cells in the pancreatic islets. Diabetes 62:2879-2889

45. Suschek C, Fehsel K, Kroncke KD, Sommer A, Kolb-Bachofen V (1994) Primary cultures of rat islet capillary endothelial cells. Constitutive and cytokine-inducible macrophagelike nitric oxide synthases are expressed and activities regulated by glucose concentration. Am J Pathol 145:685-695

46. Carlsson PO, Andersson A, Jansson L (1998) Influence of age, hyperglycemia, leptin, and NPY on islet blood flow in obesehyperglycemic mice. Am J Phys 275:E594-E601

47. Yuan L, Li Y, Li G, Song Y, Gong X (2013) Ang(1-7) treatment attenuates beta-cell dysfunction by improving pancreatic microcirculation in a rat model of type 2 diabetes. J Endocrinol Investig 36: 931-937

48. Yuan L, Lu CL, Wang Y, Li Y, Li XY (2014) Ang (1-7) protects islet endothelial cells from palmitate-induced apoptosis by AKT, eNOS, p38 MAPK, and JNK pathways. J Diabetes Res 2014:391476

49. Zhang Z, Yang L, Lei L, Chen R, Chen H, Zhang H (2016) Glucagon-like peptide-1 attenuates advanced oxidation protein product-mediated damage in islet microvascular endothelial cells partly through the RAGE pathway. Int J Mol Med 38:1161-1169

50. Agudo J, Ayuso E, Jimenez V et al (2012) Vascular endothelial growth factor-mediated islet hypervascularization and inflammation contribute to progressive reduction of beta-cell mass. Diabetes 61:2851-2861

51. Feng ZC, Popell A, Li J et al (2015) c-Kit receptor signaling regulates islet vasculature, beta-cell survival, and function in vivo. Diabetes 64:3852-3866

52. Brissova M, Aamodt K, Brahmachary P et al (2014) Islet microenvironment, modulated by vascular endothelial growth factor-A signaling, promotes beta cell regeneration. Cell Metab 19:498-511 